\title{
Research on Carbon Emissions Trading System in Electricity Market
}

\section{Zhang Qing}

\author{
Department of Economic Management, North China Electric Power University, Baoding, China \\ 23571581@qq.com
}

Keywords: Electric power industry, Carbon emission right, Trading system

\begin{abstract}
In recent years, the issue of global climate change has become increasingly prominent, the International convention on setting the relevant countries of greenhouse gas emission limits and emission reduction obligations, making carbon emissions, carbon emissions trading has become a research hotspot. Power industry as an important area of carbon emissions, but also an important sector to achieve carbon emissions, is the key to achieve emission reduction targets. Through the establishment of carbon emissions trading platform can effectively use the role of market power industry to reduce emissions costs. This paper analyzes the problems and obstacles in the implementation of carbon emissions trading system in China, and puts forward improvement measures, hoping to provide reference for the construction of carbon trading system in electricity market.
\end{abstract}

\section{Introduction}

Europe and other developed countries for carbon emissions trading system has a deep research, many aspects of the system of the contents of the market, China has not yet established effective trading system, so relatively perfect theory system of foreign carbon trading system established in accordance with China's actual reference. In 1992, more than and 150 countries passed the United Nations Framework Convention on climate change (UNFCCC) at the United Nations Conference on environment and development, aimed at limiting emissions of gases within the reach of climate [1]. In 1997 countries signed (Kyoto Protocol) regulations in 2008 2012 years will reduce emissions from 1990 5.2\% basis, and puts forward the market mechanism: joint implementation mechanism, the international emissions trading mechanism, clean development mechanism, promote the establishment of carbon emissions trading market. The current international has formed a carbon emissions trading market, but between the various trading markets, poor liquidity, needs to be further improved [2].

In the establishment of the trading market system, In the use of property rights theory on carbon dioxide emissions trading for the analysis and investigation, put forward to use the market mechanism to configure the capacity of resources, make carbon emissions can be exchanged, carbon emissions in the low marginal cost and marginal cost is higher among enterprises to provide administrative supplement must also improve the relevant legal system, which is the market allocation of resources. This paper expounds the operation status of EU Emission Trading System and clean development mechanism, and analyzes the implementation of clean development mechanism in China and its risks and benefits [3-4]. Li bu 2010, Cao Hualei (2010) analyzed the basic characteristics of EUETS and its remarkable achievements in promoting financial industry innovation, forming price mechanism, enhancing the right to speak in international negotiations, mastering transaction pricing rights and so on [5]. Zeng Ming, Yang Lingling (2010) based on the theory of carbon emissions trading and carbon tax on the application model of two kinds of mechanism are studied, the comparative analysis of cost reduction and reduction effect and gives the two, finally combined with the characteristics of the industry of electric power industry China proposed, in the short term can use carbon tax policy industry to promote technological transformation and structural adjustment, the long term should be established as soon as possible for domestic carbon emissions trading market system, the timely introduction of the electric power industry quota of carbon emissions trading pilot. 


\section{Construction of Carbon Emission Trading System}

The electric power system reform implemented in 2015 gradually promote market-oriented, realize the power industry to make hair lose, sale each link more enough to achieve market dominance, at present, China's power industry non market environment, the implementation of carbon emissions trading to increase the cost of electric power enterprises, price changes lagged behind, the lower profits, greatly weakened the enthusiasm of participating in the carbon trading system of the electric power industry therefore, in the construction of electric power to the carbon trading system, considering China's actual electricity market.

One of the difficulties in establishing carbon emissions trading system is China power of social and economic development on the formation of carbon demand continues to grow, which forced the total emissions of carbon emissions trading system cannot be achieved in the country. To achieve China's goal of reducing carbon emissions intensity, that is, in 2020 than in 2005 the unit GDP carbon emissions fell by $40 \%$ to the target of $45 \%$. By referring to the successful experience of foreign carbon emissions trading system, combined with China's actual situation, design carbon emissions trading system in line with the actual situation of China's power industry. Carbon emissions trading system mainly includes: determining the total rules of carbon emissions, quotas market (Preliminary), the transaction market and government supervision and management [6-7]. As Figure 1.

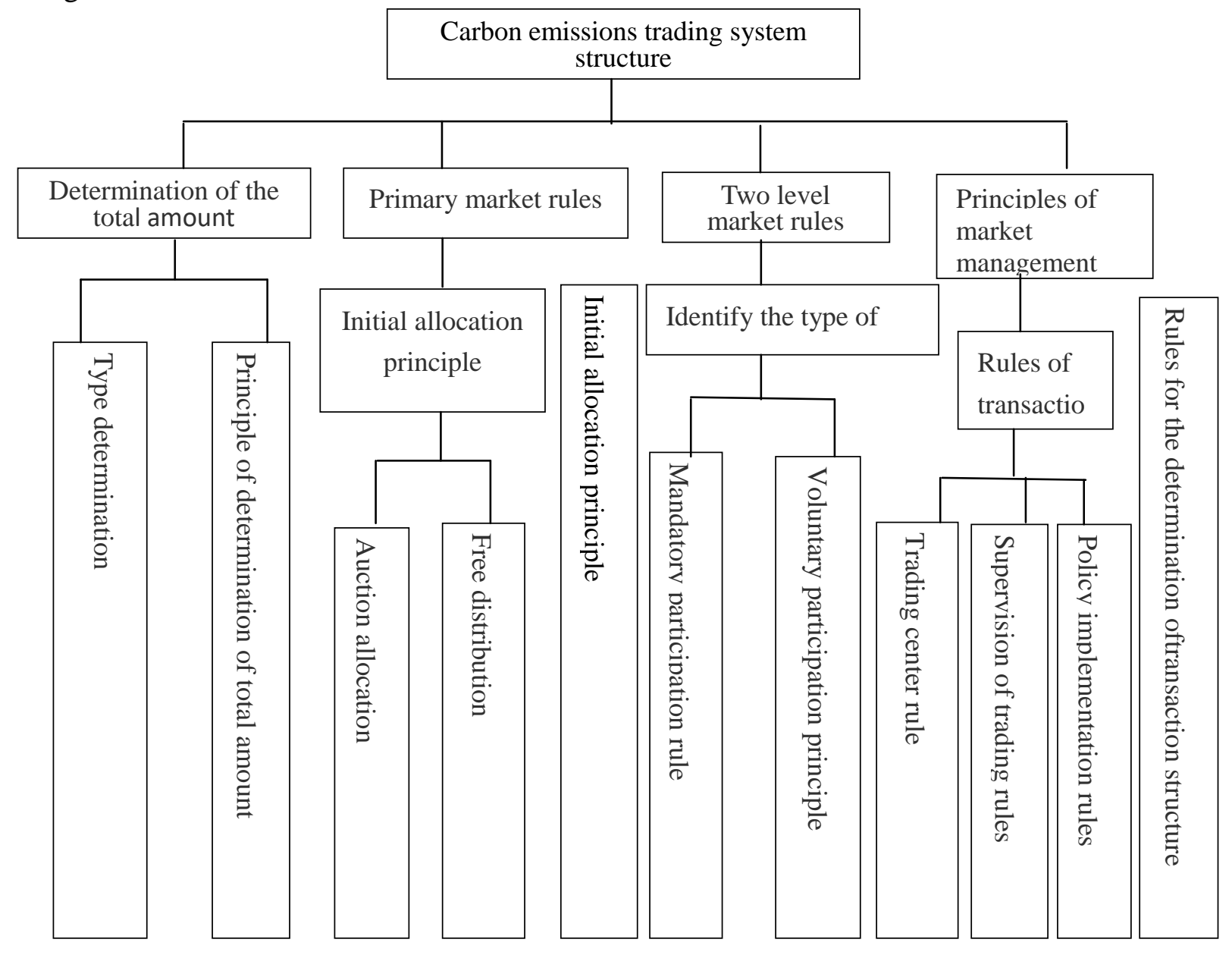

Figure 1 Carbon emissions trading system

Total Limit System. The total carbon emission limitation system includes defining the types of pollutants, according to which method to determine the total emissions of a certain region, as well as carbon emission rights deadline. Construction of the electricity carbon emissions trading system must be to achieve emission control as the premise, because only control the total carbon emissions of the use of space to limit carbon emissions are scarce, carbon emissions right can be traded as a commodity in the market. 
Initial Allocation of Carbon Emission Rights. The main way is free payment and auction. The initial emission rights auction is to internalize the external environment pollution, is on the market price distortion correction, auction and free distribution of two ways of fairness, transaction cost, compare the influence on the competitiveness of the three aspects, the initial quota auction way in various aspects are better than the free distribution.

Give full Play to the Guiding Role of Government Policy. Improve the legal system, establish a carbon financial system with international docking, train professionals, strengthen enterprise risk awareness, in order to strengthen the management of transaction risk. At the same time, the implementation of China's emissions trading system needs to establish a strict regulatory system for trading activities, in order to collect, grasp the transaction information to track the whereabouts of the sewage indicators and monitor the transaction behavior.

\section{Carbon Emissions Trading System Problems}

Although after years of efforts, China has achieved good results in the exploration of carbon emissions trading system, the rapid development of power enterprise projects, China has become the world's largest supplier of carbon emissions rights. But for China, carbon emissions trading is a new thing, has not really set up a carbon emissions trading system. During the exploration of the carbon emissions trading system, some problems are found, which restrict the establishment of China's carbon emissions trading market [8-9].

The Initial Allocation System of Carbon Emission Rights is not Perfect. Whether the power carbon emissions trading system is effective is based on a fair and equitable initial distribution system. At present, China has not yet entered the stage of mandatory emission reduction, mainly did not solve the fair allocation of carbon emissions rights in the region and power generation enterprises [10].

Carbon Quota Allowed for Trading not Determined. The effective formation of tradable carbon quota is to save carbon emissions by traditional energy conservation measures. Based on the enterprise China emission measurement of greenhouse gas emissions is relatively weak, lack of regulatory capacity, enterprises may have excess emissions and rows leakage impulse, and then lost due to excess emissions of carbon emissions and the purchase of enthusiasm.

Trading Platform cannot fully Play a Role. The establishment of China's carbon trading platform is numerous, but the regional characteristics of the trading platform is obvious, cannot achieve the timely transfer of market information. The establishment of the platform mainly reflects the government's low-carbon achievements, and there is no effective operation. Because there is no mandatory emission reduction mechanism, carbon emissions trading is less.

\section{Carbon Emissions Trading System Improvement Proposals}

Gradually Adopt Mandatory Carbon Emissions Trading. At the present stage of China's economy in the new normal stage, economic growth slowed, the development trend of the industry, and increasingly serious haze weather makes use of coal with strict control, to speed up the implementation of new energy household, making carbon emissions are more uncertain, so at this stage to voluntary transactions the mechanism of carbon emissions, an effect of the economic slowdown in the adjustment period, on the other hand, according to the assessment of their ability to achieve clean energy transformation, relatively stable after the transition to mandatory carbon emissions trading mechanism.

Formulate the Initial Allocation of Scientific Carbon Emissions Rights. In the selection of the initial allocation of carbon emission rights indicators, should fully consider the resource endowment and the current China, namely coal for power supply structure linked dominant, embodies the objectivity of carbon emissions trading, fairness and balance. In the pilot stage of carbon emissions trading, the emission quota can be determined by historical average emission principle; In the comprehensive promotion of carbon emissions trading stage, the pilot has adopted 
the principle of the latest power companies to allocate carbon emissions quotas, while the pilot companies use historical average emission principles to determine their carbon emissions quotas.

Establish a Unified Trading Platform for Carbon Emission Permits. As China's regional economic development is not balanced, each region should be based on regional driving principles, the establishment of a number of regional trading platform. Through a certain period of running in and development, gradually integration, and ultimately the formation of a unified national emissions trading platform. In addition, the establishment of entity trading platform at the same time, should actively build network trading platform. The use of online trading platform, the power enterprises can make the carbon emissions trading online, buy emissions inadequate to fulfill their commitments, or sell the quota for additional profit. In addition, the establishment of online trading platform is beneficial to the public and other subjects of the market transaction status of the market solution.

Give full Play to the Role of Government Supervision and Management. The effective operation of carbon emissions trading system needs not only the sound and perfect policies to protect, but also the government's policy support for energy conservation and emission reduction. First, according to the new access to power enterprises production technology and conditions, given paid distribution incentives. For actively reducing and participating in carbon emissions trading power companies, especially new energy companies give funding, technical and tax incentives. Second, to tax credit and other economic means for power companies to guide carbon emissions trading, in order to ensure the stability of the carbon emissions market. Third, to encourage innovation in environmental protection and low carbon technology, by accelerating the development of low energy consumption, less pollution and clean energy, the transformation of the original high emissions of technical equipment and production processes to achieve the power industry structure adjustment, thereby reducing carbon dioxide emissions.

\section{Acknowledgement}

This research is supported by the Fundamental Research Funds for the Central Universities (2016MS125).

\section{Reference}

[1] Yu Tianfei, After the analysis on carbon emissions trading property [J]. Journal of Northeast Agricultural University (SOCIAL SCIENCE EDITION), 2007,02:101-103.

[2] Liu Xiaochuan, Wang Cengtao. Carbon dioxide emission reduction policy comparison and optimization of China [J]. Journal of Shanghai University of Finance and Economics, 2009,04:73-80 88

[3] Zhang Jian, Liao Hu, Liang Qinfeng, Zhou Zhijie, Yu guangsuo. Carbon tax and carbon emissions trading of China industries [J].modern chemical industry, 2009,06:77-82.

[4] QuRuxiao, Wu Jie. Carbon emissions trading environment effect and countermeasure research [J]. Journal of Beijing Normal University (SOCIAL SCIENCE EDITION), 2009,06:127-134.

[5] Wang Xianming. Feasibility analysis of carbon emission trading in China [J]. Journal of National School of Administration, 2009,06:20-23.

[6] Zhou Wenbo, Chen Yan. On the status quo, problems and Countermeasures of China's carbon emissions trading market $[\mathrm{J}]$. Journal of Jiangxi University of Finance and Economics, 2011,03:12-17.

[7] Wang Zhonghui. EU emissions trading mechanism and Its Revelation to China's carbon emissions trading mechanism [J]. China development, 2011,04:24-28.

[8] Wang Yigang. Design of China's carbon emissions trading system [D]. Graduate School of Chinese Academy of Social Sciences, 2010 
[9] Yang Lingling, Ma. The spring power allocation model of carbon emissions in the electricity market environment [J].comparative study of Shaanxi electric power, 2010,02:5-9.

[10] Sun Liang. Construction of carbon emission trading system in China [D]. China University of Political Science and Law, 2009 